\title{
A RETROSPECTIVE STUDY OF CANNABIS USE-ASSOCIATED PSYCHOPATHOLOGY IN A SOUTHERN NIGERIA TREATMENT FACILITY
}

\author{
O. J. Oshodi ${ }^{1}$ \\ O. C. Ikeji ${ }^{1}$ \\ S. O. Olotu ${ }^{1}$ \\ O. F. Ihenyen ${ }^{1}$ \\ H. O. Obianwu ${ }^{2}$ \\ ${ }^{1}$ Psychiatric Hospital, Uselu, Benin City, Nigeria \\ ${ }^{2}$ Department of Pharmacology \& Toxicology, University of Benin, Benin City, Nigeria
}

\begin{abstract}
Hospital records of patients seen between 1999 and 2002 were carefully examined. A questionnaire was used to extract relevant information from the case records and clinical diagnosis was made using the ICD-10. Cases that had evidence of pre-existing psychiatric disorder, family history of mental illness or heavy use of alcohol and/or tobacco were excluded.

Out of 6,556 patients that were seen for the first time, 849 were drug-related cases and 601 of these were primarily cannabis users. A substantial number (83\%) of these were young and presented with severe psychopathologies. About $90 \%$ and $47 \%$ were diagnosed with psychotic disorders and dependence syndrome, respectively. It is concluded that cannabis use is associated with severe psychopathologies and constituted over $70 \%$ of demand for treatment.
\end{abstract}

KEY WORDS: Cannabis, Psychopathologies, Retrospective Study, Nigeria.

\section{INTRODUCTION}

Cannabis is the most commonly abused illicit drug in the world. Out of some 200 million persons (or $5 \%$ of the world population aged 15 - 64) estimated to have used drugs in 2003/2004; 160.9 million (or $4 \%$ of world population aged $15-64$ ) used cannabis. Cannabis use is associated with a variety of psychotic symptoms and exacerbates those of schizophrenia (UNODC, 2007). The annual prevalence of use of cannabis, cocaine, the amphetamines and opioids (as \% of the population aged $15-64$ ) in Nigeria in 2004 was $13.8 \%, 0.5 \%, 1.1 \%$, and $0.6 \%$, respectively (UNODC, 2007). Cannabis is not indigenous to Nigeria and was probably introduced to the country during and after the Second World War by members of the Nigerian armed forces returning from the Middle East, Far East and North Africa (Asuni, 1964).

Cannabis is the primary drug of abuse of most persons treated for drug -related problems in Nigeria. It accounted for $85.7 \%$ of demand for treatment in 2003 ((UNODC. 2007).

Comparable figures for opiates and cocaine were $3.7 \%$ and $0.6 \%$ respectively. Cannabis abuse-related problems were first reported in Nigeria in the 1960s.

Early studies include 16 case records of patients with cannabis-related psychosis seen at the neuropsychiatric hospital, Aro, Abeokuta,

Corresponding author: Professor H.O Obianwu, Department of Pharmacology and Toxicology, University of Benin, PMB 1154, Benin City, Nigeria. Telephone: 234 8023160287; E-mail: hopeobianwu@yahoo.com 
Nigeria (Asuni, 1964); report that $15 \%$ of patients admitted to the same hospital in 1959 -1960 were related to cannabis use (Lambo, 1965). The same author reported that $20 \%$ of the outpatients seen for psychiatric management at the University College Hospital, Ibadan, Nigeria were related to cannabis. Others include report of a steady increase in the percentage of patients admitted at the psychiatric hospital, Yaba, Lagos, Nigeria with a history of cannabis use from $8.1 \%$ of all admissions in 1961 - 1962 to $21 \%$ in 1964-1965 (Boroffka, 1966); two cases of psychosis following ingestion of cannabis by a three and an eleven year old children (Binitie, 1975); comparison of 33 patients that presented with cannabisassociated psychosis with 25 paranoid schizophrenics in which it was noted that the clinical features of the two groups were similar (Sijuwola,1986). This study could not substantiate the existence of cannabis psychosis as an independent disorder.

In a study of case records of patients admitted for drug and alcohol - related problems in psychiatric treatment facilities in the Northern and Southern parts of Nigeria, cannabis abuse was recorded for $77 \%$ of the patients in the Northern part of the country while $60.6 \%$ was recorded for the Southern based facilities (Ohaeri and Odejide, 1993). No details of cannabis - associated psychopathologies were provided. A study in which some details of symptom patterns associated with cannabis use were provided did not exclude cases with histories of psychiatric disorders (Imade and Ebie, 1991). The patient populations of these studies were limited and/or the studies did not provide adequate details of patterns of psychopathologies associated with cannabis abuse. The present study was designed to provide details of pattern of psychopathologies and their prevalence in a large number of patients treated for cannabis - related problems over a period of four years.

\section{METHODS}

Location: The study was carried out in the psychiatric hospital, Uselu, Benin City, Nigeria. The hospital is a 221 bedded psychiatric care facility and provides inpatient and outpatient mental health services. Benin City is the capital of Edo State, one of the 36 States in Nigeria. The hospital serves as a referral and treatment centre for six of the thirty six states. It is adequately staffed with consultant psychiatrists, resident doctors, clinical psychologists, psychiatric nurses, social workers and other support staff.

Sample: The hospital records for the period January 1999 - December, 2002 were reviewed. Drug - related cases were identified and those cases with evidence of psychiatric disorders prior to use of cannabis, family history of mental illness or heavy use of alcohol and/or tobacco and other drugs such as the amphetamines were excluded from the study.

Instrument: A 76 - item questionnaire designed in standard manner of history taking in psychiatry by the authors was used to extract relevant information from the case records. The information included socio-demographic characteristics, past medical history, drug use history, family history, pattern of psychopathological symptoms presentations and diagnosis. Others include duration of illness, hospitalization when applicable, mode of management and follow-up of clinic attendance after first presentation or after discharge from admission.

Procedure: The study was carried out retrospectively from April to December, 2004. The case records were first sorted in the records department with the help of the medical clerks. They were carefully examined by the psychiatrists. Clinical diagnosis was carried out based on the ICD-10 (WHO, 1992). Permission to carry out the study was obtained from the Review Board of the hospital.

Data analysis: Statistical Package for the Social Sciences, version 11.0 (SPSS, 2001) was used to analyze for frequency counts, measure of central tendency and dispersion and partial Spearman Rho correlation analysis following the distribution of the sample at five percent level of statistical significance. 


\section{RESULTS}

\section{Socio-demographic Characteristics}

Table 1 shows that the cases were predominantly young, single males who had completed senior secondary education. There was no significant difference between the ages of both sexes $(t=-1.41, \mathrm{df}=559, p=0.16)$. Most of the cases were of the lower socioeconomic group and were unemployed.

\section{Clinical characteristics}

Out of the 6,556 patients that were seen for the first time, 849 (13\%) were drug - related cases. Eighty four percent (712) of the drug cases were cannabis - related out of which 601 (70.8\%) were primarily cannabis users. Half of the 601 cases $(49.3 \%)$ used cannabis for less than one year, $28 \%$ (168) used cannabis for one to five years, $12 \%(72)$ of the cases used for five to ten years and $10.8 \%$ (65) of the cases used cannabis for more than ten years. Ninety - six percent (575) of the cases used cannabis by smoking, $1.7 \%$ (10) ingested cannabis orally (used it to prepare stew and other food items) and $2.7 \%$ (16) of the cases smoked and ingested cannabis.

Pattern of psychopathology presentations and clinical psychiatric diagnoses

Tables 2 and 3 show the pattern of psychopathology presentations and clinical psychiatric diagnoses among the cases, respectively.

The mean duration of hospitalization for those admitted was 6.91 weeks with a standard deviation of 3.90 .

There was a moderate significant correlation between admission at first presentation and the number of relapse (Spearman Rho correlation, $\mathrm{r}=0.58, \mathrm{p}<0.01$, details not shown).

For all the cases, there was a low significant positive correlation between age and the duration of cannabis use $(r=0.31, p<0.01)$.

There was a little significant negative correlation between ages of the cases and dependence due to cannabis use $(r=-0.20, p<0.01)$ which did not change after controlling for sex following a partial correlation, $\mathrm{N}=507, r=$ $0.22, p<0.01$.
Table 1. Sociodemographic

characteristics of the sample $(\mathrm{N}=601)$

\begin{tabular}{|c|c|c|}
\hline Variable & n & $\%$ \\
\hline \multicolumn{3}{|l|}{ Sex } \\
\hline Male & 588 & 97.8 \\
\hline Female & 13 & 2.2 \\
\hline
\end{tabular}

$\begin{array}{ll}\text { Mean Age (SD) } & \\ \text { Total Group } & 25.20(5.57) \\ & 25.15(5.69) \\ \text { Male } & 27.38(3.97)\end{array}$

Female

$\begin{array}{lcc}\text { Age Group (Years) } & & \\ 15-19 & 49 & 8.2 \\ 20-24 & 271 & 45.0 \\ 25-29 & 179 & 29.8 \\ 30-34 & 62 & 10.3 \\ 35-39 & 23 & 3.8 \\ 40 \text { and above } & 17 & 2.9\end{array}$

Marital Status

Never married $\quad 559 \quad 93.0$

$\begin{array}{lll}\text { Married } & 31 & 5.2\end{array}$

$\begin{array}{lll}\text { Separated } & 9 & 1.4\end{array}$

Divorced $\quad 1 \quad 0.2$

$\begin{array}{lll}\text { Widowed } & 1 & 0.2\end{array}$

Highest level of education

$\begin{array}{lll}\text { No formal education } & 7 & 1.1\end{array}$

Primary education $\quad 166 \quad 27.6$

Junior secondary education $\quad 63 \quad 10.5$

Senior secondary education $\quad 284 \quad 47.3$

$\begin{array}{lll}\text { Tertiary education } & 81 & 13.5\end{array}$

Occupation

Unemployed $\quad 245 \quad 40.8$

$\begin{array}{lll}\text { Students } & 146 & 24.3\end{array}$

$\begin{array}{lll}\text { Artisans }^{\mathrm{a}} & 130 & 21.6\end{array}$

$\begin{array}{lll}\text { Traders } & 37 & 6.2\end{array}$

$\begin{array}{lll}\text { Farmers } & 21 & 3.5\end{array}$

$\begin{array}{lll}\text { Civil servants } & 8 & 1.3\end{array}$

$\begin{array}{lll}\text { Others }^{\mathrm{b}} & 14 & 2.3\end{array}$

a: includes welders, carpenters, auto mechanics, plumbers and electricians

b: includes butchers, fishermen, motor bike operators.

In addition, there were low significant negative correlations between the duration of cannabis use and dependence syndrome $(r=-$ $0.31, p<0.01)$, between the route of cannabis use and acute intoxication $(r=-0.15, p<0.01)$ 
Table 2. Patterns of presentation of psychopathology

\begin{tabular}{|c|c|c|c|}
\hline Psychopathology & $\begin{array}{c}\text { Inpatient } \mathbf{N}=300 \mathrm{~F} \\
(\%)\end{array}$ & $\begin{array}{c}\text { Outpatient } \mathbf{N}=301 \\
(\%)\end{array}$ & $\begin{array}{c}\text { Total } N=601 \\
(\%)\end{array}$ \\
\hline \multicolumn{4}{|l|}{ Psychotic Symptoms } \\
\hline Over activity/restlessness & $180(62.7)$ & $158(59.8)$ & $346(57.6)$ \\
\hline Delusion & $172(57.3)$ & $130(43.2)$ & $302(50.2)$ \\
\hline Hallucinations & $135(45.0)$ & $132(43.9)$ & $267(44.4)$ \\
\hline Psychomotor retardation & $42(14.0)$ & $45(15.0)$ & $87(14.5)$ \\
\hline Catatonia & $23(7.7)$ & $21(7.0)$ & $44(7.3)$ \\
\hline \multicolumn{4}{|l|}{ Schizophrenia-like symptoms } \\
\hline Change in behaviour & $145(48.3)$ & $121(40.2)$ & $266(44.3)$ \\
\hline Irrelevant speech & $101(33.7)$ & $75(24.9)$ & $176(29.3)$ \\
\hline Negative symptoms & $49(16.3)$ & $51(16.9)$ & $100(16.6)$ \\
\hline Thought disorders & $22(7.3)$ & $24(8.0)$ & $46(7.7)$ \\
\hline \multicolumn{4}{|l|}{ Other psychiatric symptoms } \\
\hline Disturbed sleep & $164(54.7)$ & $169(56.1)$ & $333(55.4)$ \\
\hline Irritability & $153(51.0)$ & $118(39.2)$ & $271(45.1)$ \\
\hline Talkativeness & $120(40.0)$ & $82(27.2)$ & $202(33.6)$ \\
\hline Impaired concentration & $61(20.3)$ & $92(30.6)$ & $153(25.5)$ \\
\hline Elevated mood & $88(29.3)$ & $51(16.9)$ & $139(23.1)$ \\
\hline Depressed mood & $34(11.3)$ & $65(21.6)$ & $99(16.5)$ \\
\hline Impaired judgment & $46(15.3)$ & $48(15.9)$ & $94(15.6)$ \\
\hline Reduced appetite & $41(13.7)$ & $17(12.3)$ & $78(13.0)$ \\
\hline Anxiety & $25(8.3)$ & $50(16.6)$ & $75(12.5)$ \\
\hline Reduced energy levels & $19(6.3)$ & $45(15.0)$ & $64(10.6)$ \\
\hline Anhedonia & $12(4.0)$ & $22(7.3)$ & $34(5.9)$ \\
\hline Others $^{\mathrm{a}}$ & $6(2.0)$ & $27(9.0)$ & $33(5.5)$ \\
\hline
\end{tabular}

a: includes anxiety symptoms such as sensitivity to noise, worry thoughts, palpitations, chest discomfort, tremors, paraesthesia, dizziness, headache, flatulence, etc. affective symptoms such as extravagant spending, over familiarity, marked increase in sexual energy or indiscretion, marked loss of libido, ideas of guilt, reduced self-esteem and thoughts of suicide or suicidal behaviours.

Table 3. ICD-10 psychiatric diagnoses due to the use of cannabis

\begin{tabular}{lccc}
\hline \multicolumn{1}{c}{ Diagnosis } & $\begin{array}{c}\text { Inpatients, } \mathbf{N}=\mathbf{3 0 0} \\
\mathbf{( \% )}\end{array}$ & $\begin{array}{c}\text { Outpatients, } \mathbf{N}=\mathbf{3 0 1} \\
\mathbf{( \% )}\end{array}$ & $\begin{array}{c}\text { Total, } \mathbf{N}=\mathbf{6 0 1} \\
\mathbf{( \% )}\end{array}$ \\
\hline Acute intoxication & $2(0.7)$ & $2(0.7)$ & $4(0.7)^{\mathrm{a}}$ \\
Harmful use & $3(1.0)$ & $10(3.3)$ & $13(2.2)^{\mathrm{a}}$ \\
Dependence syndrome & $171(57.0)$ & $112(37.2)$ & $283(47.1)^{\mathrm{a}}$ \\
Psychotic disorders & $275(91.7)$ & $265(88.0)$ & $540(89.9)^{\mathrm{a}}$ \\
Amnestic syndrome & $1(0.3)$ & $1(0.3)$ & $2(0.3)$ \\
Residual and late onset of & $5(1.7)$ & $15(5.0)$ & $20(3.4)$ \\
psychotic disorder & & & \\
\hline
\end{tabular}

${ }^{\text {a: }}$ multiple diagnosis was recorded for some cases. The difference between the actual total is due to multiple diagnosis.

and a low significant positive correlation between the route of cannabis use (smoking) and psychotic disorders $(r=0.15, p<0.01)$. A large number of the cases presented with significant psychotic, schizophrenia-like and other psychiatric symptoms.

\section{DISCUSSION}

A review of the hospital records at the psychiatric hospital, Uselu, Benin City in southern Nigeria between January 1999 and December, 2002 showed that $13 \%$ (849) of the 6,556 pa- 
tients who presented (first seen ) for management were drug - related cases. This figure is much higher than that reported for southern part of Nigeria in 1989 (Ohaeri and Odejide, 1993). Further, eighty four percent (712) of the drug cases were cannabis related and $70.8 \%$ (601 cases) used cannabis as the primary drug of abuse.

The estimated treatment demand for cannabis associated problems (primary drug of abuse) in Nigeria in 2003 was 85.7\% (UNODC, 2007). There appears therefore to be a steady increase in the demand for treatment of cannabis use - related cases (see also Boroff$\mathrm{ka}, 1966)$. Young adults between the ages of 20 and 29 represented $74.8 \%$ (450) of the cases, most of who were of low socioeconomic background and unemployed (table 1).

Patterns of psychopathology presentation and psychiatric diagnoses are shown in tables 2 and 3, respectively; Psychotic disorders were diagnosed for a very large proportion of the cases $(89.9 \%$, table 3$)$. The proportion diagnosed for dependence syndrome was $47.1 \%$ (table 3). The present study shows that a significant proportion of the cases were diagnosed with severe psychiatric disorders.

Earlier reported studies of cases of cannabis-associated psychotic disorders in Nigeria involved much fewer patients and/or the symptoms reported were not as detailed as in the present study (see Asuni, 1964, Lambo, 1965, Boroffka, 1966, Binitie, 1975, Sijuwola, 1986, Imade and Ebie, 1991 and Anumonye, 1980). There was no indications in these earlier studies that patients with history of mental disorders or use of other drugs were excluded. Globally, there are several reports of psychosis following use of cannabis (see for example, Chopra and Smith, 1974, Andreason et al,.1987, Hall and Dagenhardt, 2000, Dennis et al., 2002, Henquet, et al., 2005, Ferguson et al., 2006 ).

In contrast, a few studies did not find clear association between cannabis use and psychosis (see Imade and Ebie, 1991, Thornicroft, Meadows and Politip, 1992). There is now a general agreement that cannabis use is associated with psychosis but there is still debate on whether cannabis use causes psychoses or precipitates it in susceptible persons (Arseneault et al, 2004). However, it is important to observe that the use of cannabis carries a risk of psychiatric morbidity. Whether this risk is higher if the user is predisposed to psychiatric disorders is secondary to the fact that the use of cannabis has potential of resulting in serious mental problems.

Cannabis grows wild in many parts of Nigeria, in particular the Mid West (Edo and Delta States) and the South West (Ondo and Osun States). It is very cheap compared to other substances of abuse, including alcohol. For example, the cost of one wrap of cannabis cigarette in Benin City is about 8 US cents. A bottle of popular locally produced beer of $600 \mathrm{ml}(5.1 \%$ volume alcohol content) costs equivalent of one US dollar. Because of its availability and low cost, regular cannabis users in Nigeria tend to use it heavily. Cannabis is usually sold in "bundles" (a bundle weighs 6-10 grams depending on the quality). Five to seven wraps of cigarette are prepared from a bundle.

In an attempt to obtain information on the pattern of use of cannabis, ten of the patients with cannabis-related problems who presented at the hospital for management during this study were randomly selected and carefully interviewed about their use of cannabis. Use of cannabis by these patients ranged between 14 and 42 wraps per week with a mean of 14 wraps per week Four of them indicated that they started using cannabis before they were 15 years old. The ten patients stated that the complaints of their parents, siblings and / or friends about their drug use habits led to their visit to the hospital (details not shown).

A possible reason for the rarity of "cannabis psychosis" in Western societies is that cannabis psychosis probably occurs after periods of its sustained heavy use (Hall and Dagenhardt, 2000). A search of cannabis literature did not provide a standard description of its "heavy use". For example, heavy use has variously been described as more than 10 times per month (Kendler et al,. 2000); more than 40 times without specification of what period (Miller and Plant, 2002); more than 50 times 
without indication of what period (Zammit et al., 2002). Although lifetime use of cannabis has increased in Western Societies, the pattern of heavy use is probably not as intense and common as in societies where it is readily available and very cheap. Although presence of cannabinoid in urine or blood was not established in the cases of the present study, evidence of cannabis use relied strongly on clinical signs and symptoms of cannabis stigmata and careful history taking of the patients' drug use. Self and informants' reports of cannabis use provide additional confirmation of its use (Woody and MacFadden, 1995).

In any case, absence of cannabis in blood or urine does not necessarily prove that cannabis is not implicated in the psychopathology and vice versa. For example, alcohol - related hallucinations can persist for weeks with no detectable amount of alcohol in the blood (Hall, 1988). Abuse of stimulants such as the amphetamines is very low in Nigeria (UNODC, 2007) and most of the cases studied were unemployed and possibly could not afford the cost of such other drugs which are much more expensive than cannabis in Nigeria. Despite the imperfections and uncertainties of the available epidemiological evidence, acute intoxication and chronic use of cannabis appear to be associated with negative consequences and substantial health burden (Hall and Babor, 2000).

There is now considerable evidence that indicate consistent association between cannabis use and psychotic disorders independent of confounding and transient intoxication effets (Moore et al,. 2007). The present study has provided substantial additional detailed evidence of severe psychopathology associated with cannabis use in a large number of patients in Nigeria.

\section{REFERENCES}

Andreasson, S., Allbeck, P., Engstrom, A., \& Rydberg, A. (1987). Cannabis and Schizophrenia: a longitudinal study of Swedish conscripts. Lancet, 2, $1483-1487$.
Anumonye, A. (1980). Drug use among young people in Lagos, Nigeria. Bulletin on Narcotics, 32, 39-45.

Arseneault, L., Cannon, M., Witton, J., \& Murray, R. M. (2004). Causal association between cannabis and psychosis: examination of the evidence. British Journal Psychiatry, 184, 110 - 117.

Asuni, T. (1964). Socio-Psychiatric problems of Cannabis in Nigeria. Bulletin on Narcotics, 16 (2), 27.

Binitie, A. (1975). Psychosis following ingestion of Hemp in Children. Psychopharmacologia, 44, 301-302.

Boroffka, A. (1966). Mental illness and Indian hemp in Lagos. African Medical Journal, 43, 377-384.

Chopra, G. S., \& Smith, J. W. (1974). Psychotic reactions following cannabis use in East Indians. Archives of General Psychiatry, 30, 24-27.

Dennis, M., Babor. T. F., Roeback, M. C., \& Donaldson, T. (2002). Changing the focus: the case for recognizing and treating cannabis use disorders. Addiction, 97 (Suppl.), 4-15.

Ferguson, D. M, Poulton, R., Smith, P. F., \& Boden, J. M. (2006). Cannabis and psychosis. British Medical Journal, 332, 172-175.

Hall, W., \& Babor T. F. (2000). Cannabis use and public health: assessing the burden. Addiction, 95, 485-490.

Hall, W., \& Degenhardt, L. (2000). Cannabis use and Psychosis: a review of clinical and epidemiological evidence. Australian and New Zealand J. Psychiatry, 34, 26-34.

Hall, W. (1988) Cannabis use and psychosis. Drug and Alcohol Review, 17, 433-444

Henquet, C., Krabbendam, L., \& Spauwen, J. et al. (2005). Prospective cohort study of cannabis use, predisposition for psychosis and psychotic symptoms in young people. BMJ, 330, 11.

Hollister, L. E. (1986). Health aspect of cannabis users. Pharmacology Review, 38, $1-20$.

Imade, A. G. T., \& Ebie, J. C. (1991). A retrospective study of symptom patterns of 
cannabis psychosis. Acta Psychiatrica Scandinavica, 8,134-136.

Kendler, K. S., Karkowski, L. M., Neale, M. C., \& Prescott, C. A. (2000). Illicit psychoactive substance use, heavy use, abuse, and dependence in US populationbased sample of male twins. Archives of General Psychiatry, 57, 261-269.

Lambo, T. (1965). Medical and social problems of drug addiction in West Africa with emphasis on psychiatric aspects. The West African Medical Journal, 14, 236-254.

Miller, P., \& Plant, M. (2002). Heavy cannabis use among UK teenagers: an exploration. Drug and Alcohol Dependence, 65 (3), 235-242.

More, T. H. M, Zammit, S., Lingford-Hughes, A., Barnes, T. R. E., Jones, P. B., Burk, M., et al. (2007). Cannabis use and risk of psychotic or affective mental health outcomes: a systematic review. Lancet, 370, 319-328.

Ohaeri, J. U., \& Odejide, O. A. (1993). Admissions for Drug and Alcohol related problems in Nigerian Psychiatric Care facilities in one year. Drug and Alcohol Dependence, 31, 101-109.
Sijuwola, O. A. (1986). Comparative study of psychosis associated with cannabis. West African Journal of Medicine, 5 (4), 271276.

SPSS (2001). Statistical Package for the Social Sciences (SPSS) version 11. Chicago: SPSS, Inc.

Thornicroft, G., Meadows, G., \& Politip, P. (1992). Is "cannabis psychosis" a distinct category? European Psychiatry, 7, 277-282.

United Nations Office on Drugs and Crime (UNODC; 2005). World Drug Report 2005. Vienna: UNODC.

Woody, G. E., \& MacFadden, W. (1995). Cannabis-related disorders. In: Comprehensive textbook of Psychiatry, $6^{\text {th }}$ edition, Vol 2. (pp. 810 816). Baltimore: Williams and Wilkins.

World Health Organization (1992). The International Classification of Mental and Behavioural Disorders (ICD-10). Geneva: WHO.

Zammit, S., Allbeck, P., Andreasson, S., Lundberg, I., \& Lewis, J. (2002). Self reported cannabis use in adolescence and risk for adult psychosis: longitudinal prospective study. BMJ, 325, 1212-1213. 